rollos internacionales / Argentina

\title{
Saltar del texto al mundo de la mano de una pedagogía política
}

\author{
María Lucrecia Reta* \\ Fecha de elaboración: agosto de 2005 \\ Fecha de aceptación: 28 de octubre de 2005
}

Resumen. El artículo reflexiona sobre un experimento pedagógico que tuvo como resultado la creación de una nueva forma de conocimiento, y la propuesta de un nuevo sistema educativo con mecanismos de cambio social fundamentados en la generación de conciencia. El resultado es una nueva pedagogía política que optimiza todos los recursos educativos y establece un diálogo que permite ver cómo son los esquemas de comunicación e interpretación de la realidad por parte de los estudiantes.

Palabras clave: pedagogía política, reflexión, comunicación, texto literario, interpretación, innovación social.

To jump from the text to the world guided by a political education

Summary. The article is about an educational experiment that brought as a result the creation of a new way of knowledge, and a proposal of a new educational system with social change mechanisms based on the generation of conscience. The result is a new political education that optimizes all the resources and establishes a dialogue that shows how the communication and interpretation of reality that students make, is.

Key words: political education, reflection, communication, literary text, interpretation, social innovation.

\section{Punto de partida. Convertir el aula en escena-} rio de prácticas comunicacionales auténticas. Atravesar la brecha que separa a los adolescentes de la literatura, a los alumnos de la escuela, a los docentes del placer de enseñar. Atreverse a mutaciones epistémicas vivificantes, en el propio territorio, a pesar de controles, retos, críticas. Echar mano a las nuevas figuras y modalidades que el entorno informacional posibilita. Aprovechar los intersticios que la vida cotidiana proporciona en las instituciones que, a veces sin querer, otras queriendo, fosilizan a quienes participamos en su seno. Entrenarnos en "pequeñas revanchas" para subvertir lo programado por un sistema que amolda. Entrenarnos y entrenar para el cambio. Suenan como bellas y rimbombantes declaraciones de principios, de presencia sine qua non, en una reflexión sobre práctica docente.

Mas el presente escrito intenta demostrar cómo los principios se materializaron en un proyecto áulico, Un fútbol sin pelota, que fue escrito y tomó cuerpo por y en un grupo de adolescentes argentinos. Para ello, partimos de un texto consagrado por el canon, de lectura obligatoria en quinto año: El gaucho Martín Fierro (1872) y La vuelta de Martín Fierro (1879) de José Hernández. Texto en versos, con palabras y escenarios y prácticas que huelen a moho y saben rancios. Texto considerado no un producto acabado que se agota en su lectura, en su análisis, no una estructura, sino una estructuración que permite el trabajo y el juego. Pues este "buen texto" es "un volumen de huellas en trance de desplazamiento" (Barthes, 1990).

\footnotetext{
Docente e investigadora de la Universidad Nacional del Comahue, Río Negro, Argentina. Especialista en Planificación y Gestión Social con mención en Comunicación. Actualmente elabora su tesis de posgrado. Ha participado en congresos y eventos nacionales e internacionales como expositora. Ha publicado en revistas universitarias y en revistas de interés educativo y general. Fue distinguida con una beca por International Reading Association. pugnireta@hotmail.com.
} 
La mirada a tal proyecto se hará desde una perspectiva comunicacional que permite repensar la práctica docente desde las teorías que cruzan la comunicación y la educación.

\section{Relato de una práctica. Un fútbol sin pelota}

Nos encontramos en el imponente estadio Faustino Sarmiento Arena para presenciar el partido más esperado del año, la final del campeonato de las Américas entre el vistoso Deportivo Fierro y el potente Power Futbol Club. El Deportivo Fierro va a formar de la siguiente manera: Picardía y Cruz de línea de fondo, el viejo Vizcacha de enganche y el Capitán Martín Fierro y su Hijo Segundo serán las dos puntas del conjunto dirigido tácticamente por el Káiser José Hernández. El Licenciado FMI ha decidido que su equipo el Power Futbol Club se dispondrá en la cancha de la siguiente manera: El Pibe Coima y Justicia Corrupta en la defensa, en el medio campo el Loco Desocupación y en la delantera Abuso de Poder junto con Voto Comprado. El árbitro que dirigirá este partido, a pesar de las quejas de los dirigentes del Deportivo Fierro ante la FIFA, es el Sheriff Sarmiento descendiente directo del prócer que da nombre al estadio'.

Así comienza el producto estético, el nuevo significante que ha logrado armar un grupo de alumnos de un quinto año de una Escuela Privada de General Roca, Río Negro, luego de discusiones, peleas, risas, cargadas.

¿Cómo se gesta ese nuevo constructo?

Un fútbol sin pelota debía ser escrito para luego ser representado en la Muestra del Área de Comunicación que se realiza en la escuela frente a padres, hermanos, abuelos, amigos, novios y novias, dueños de la institución, directivos, docentes.

Objetivos claros figuraban en la hoja de ruta que sucintamente describía el proyecto que debíamos presentar a la institución. Plural adrede pues desde el inicio la experiencia fue construida entre todos, ellos aportaban sus saberes, sus ideas, luego aportarían también su cuerpo. El programa de Literatura Argentina entregaba el texto de Hernández y explicitaba la metodología. El Martín Fierro era "de lectura obligatoria común al

\footnotetext{
1 Extracto del texto Un fútbol sin pelota escrito por los alumnos.
}

grupo". No estaba en esas unidades con textos para optar. Así que esta vez, libertad de elección cercenada, todos debían leerlo. Leerlo del libro, no servía ver la película, a pesar de que en otras unidades habíamos leído discursos cinematográficos. Leerlo desde una de las estrategias de abordaje al texto implementada por la cátedra, pues la materialidad textual y la intención docente así lo requerían. Y justo esta vez la estrategia propuesta era una lectura hermenéutico-literaria enlazada con una lectura histórico-política. Lejos la lectura hedonista.

Y bueno pues, porque el aprendizaje es una cuestión de encuentros, porque todo vale, cuando se trata de promover la lectura y las reglas se hacen explícitas, fue que se pensó en la pelota y la puja deportiva para sortear el abismo aparente que separaba a esos adolescentes de Fierro y los suyos.

Catorce textos de Martín Fierro asoman sobre los bancos. Uno sabe como docente que un grupo de alumnos reducido leerá como una más de las tareas escolares. Tal vez con gusto, tal vez por cumplir con el deber. Alguno, tal vez con ardor. Mas el otro grupo, el del "para qué, qué embole, para qué me sirve", se prepara para la resistencia, para la consabida negación a la lectura. Y entonces y después de tantos años, se acomodan las armas para colocar a Hernández y a Fierro junto a ellos. Junto a ellos, los alumnos, los verdaderos protagonistas, en y desde sus trincheras, en y desde su medio campo.

Por eso se eligió el fútbol, cosa que significó para la docente realizar un salto epistemológico tan desmesurado como el que le solicitaba a sus alumnos con la lectura propuesta, pues el deporte que acalora multitudes dista visceralmente de sus gustos personales. Así pues el empate en el desconocimiento, en la ignorancia, movía a emparejar la comunicación. Por momentos, movía a risa. Lejos quedaba en este tiempo escolar la figura del docente que depositaba, según el término de Freire, su saber en sus alumnos. Lejos un modelo comunicacional unidireccional y lineal a la caza de resultados. Lejos y tomando las palabras de Mata (1990: 10) "las flagrantes asimetrías de naturaleza comunicativa" que signan negativamente la relación pedagógica en la que el chico es siempre receptor y el docente siempre emisor. Cada quien podría transmitir desde su ámbito de saber. Cada quien podría "emitir en igualdad de condiciones, rechazando la subsidiariedad del rol de receptor" (Mata, 1990: 7) que la ecuación docente-alumno muchas ve- 
ces impone. Subsidiariedad que ubica al alumno como receptor y mengua su actividad (Mata, 1990: 7).

Ineludible escollo para el divertimento futuro fue la lectura individual y obligatoria, constatada en una tradicional puesta en común que respondía a la convocatoria Mateando con Martín Fierro. Puesta con ortodoxa calificación numérica, con texto en mano y requerimientos en torno a especificidades del discurso literario.

Luego se vieron en el aula partidos de fútbol, se identificaron y analizaron los rasgos lingüísticos de superficie del discurso del comentarista y del relator, de las publicidades. Los acalorados hinchas debían traducir y enseñarnos a quienes no teníamos ni idea. A veces les resultaba inverosímil nuestro grado de ignorancia $y$ cierto "no podés no saber eso" nos golpeaba la cara.

Posteriormente vino el segundo tiempo. Y nuestra revancha. La lectura o relectura en pro del futuro significante implicaba determinación de núcleos temáticos, rastreo de estrofas o versos sueltos que dieran cuenta de situaciones aún vigentes o de programas de acción propuestos por el autor, búsquedas infinitas que debían ser consignadas por escrito, expuestas, transmitidas al grupo.

Adónde íbamos a llegar, no lo sabía nadie. Un fútbol sin pelota era un desafío a la creación, era un proyecto abierto, signado por marchas y contramarchas.

Surgieron dificultades. Las contramarchas se presentaron: un grupo, tres chicas y tres varones, no se sentían movilizados por la propuesta, con el fútbol no podían inspirarse y por ello no podían proponer, ni participar con el mismo calor que el resto. La conducción docente decidió no forzar una unión que empezaba a enrarecer el funcionamiento, que alentaba "las posturas rumiantes, caracterizadas por callar la crítica en el momento y lugar oportunos para formularla como comentario al margen, mediante el rumor o en el pasillo" (Martínez Guarino, 1996: 49). Se les permitió abandonar la cancha si presentaban un proyecto que surgiera de otro de los textos del programa. Así lo hicieron. Armaron El anclaje, un programa de radio. $Y$ ambos proyectos comenzaron a transitar paralelamente para la muestra.

El empate a la hora de los resultados sobre el escenario fue gratificante.

El grupo de Fierro y el fútbol quedó conformado por ocho integrantes: cinco chicas y tres varones. Es así que debieron aceptar correrse de ciertos estereotipos futboleros. Debían integrar equipos mixtos, para poder representar con pertinencia las jugadas que se seleccio- naran; el comentarista y el relator, si iban en vivo, debían ser voces femeninas, etcétera, etcétera... Era febril el proceso de interacción grupal que iba conduciendo a generar algo diferente, empapados de gozo, sin freno en el lenguaje, en los gestos, en las demostraciones. Todos aportaban, el proyecto permitía a cada uno "ser dueño de sus propias posibilidades, no importaba si físicas, intelectuales" (Prieto Castillo, 1990). El aula era una fiesta, nos divertíamos, superábamos cierta negación del goce que acompaña y empaña al conocimiento. Desde el humor, o el rigor que el texto fuente imponía, los hinchas generaban, las chicas imponían ciertos límites. ¿Roles estancos? ¿Adhesión a "normas androcéntricas y sexistas"? (Alfaro Moreno, 1999: 43). Nada de ello, a la hora de la representación unos y otros cedieron en virtud del resultado y en virtud de cierta postura docente que convertía la certeza en duda y la "sospecha en fuerza de cambio" (Alfaro Moreno, 1999: 36).

¿Cómo denominar a los jugadores del equipo contrario al de Fierro? ¿Cómo serían las camisetas? ¿Quién iba a ganar el partido? ¿Cuáles serían las jugadas? ¿Qué virtudes y defectos destacar en cada jugador, en el árbitro, en la platea? ¿Qué publicitar? ¿Qué música de entrada a la cancha? ¿Quiénes darían la vuelta a la cancha, todos, sólo quienes ganaran? ¿Qué núcleos temáticos privilegiar? ¿Qué citas usar? ¿Cómo recitar los versos de Hernández? Interrogantes que iban respondiendo acaloradamente.

Finalmente presentaron el texto. Fue corregido y vuelto a presentar. Lo aprobaron.

\section{Repensar las prácticas, junto a Verón, Barbero, Mata, Uranga...}

Relator: El Káiser Hernández da la orden y empezaron los 90 minutos del deporte más hermoso del mundo. Vizcacha que movía para Picardía. Picardía que la abre para Hijo Segundo. Hijo Segundo que amaga y se lanza para lateral derecho, la tira al medio para Picardía, la pisa, pisa y... ¡Oso!, ¡Ole! Justicia Corrupta que pasa de largo. Sigue Picardía, le abre. ¡Uh! Justicia Corrupta que lo barre con los tapones hacia arriba.

Lita: Ese jugador claramente no fue a la pelota, fue directamente a bajar a Picardía, esto es para roja directa acá y en la China. Se equivocó groseramente el Sheriff Sarmiento, que se quedó mirando como si nada haciendo señas de siga, siga. 


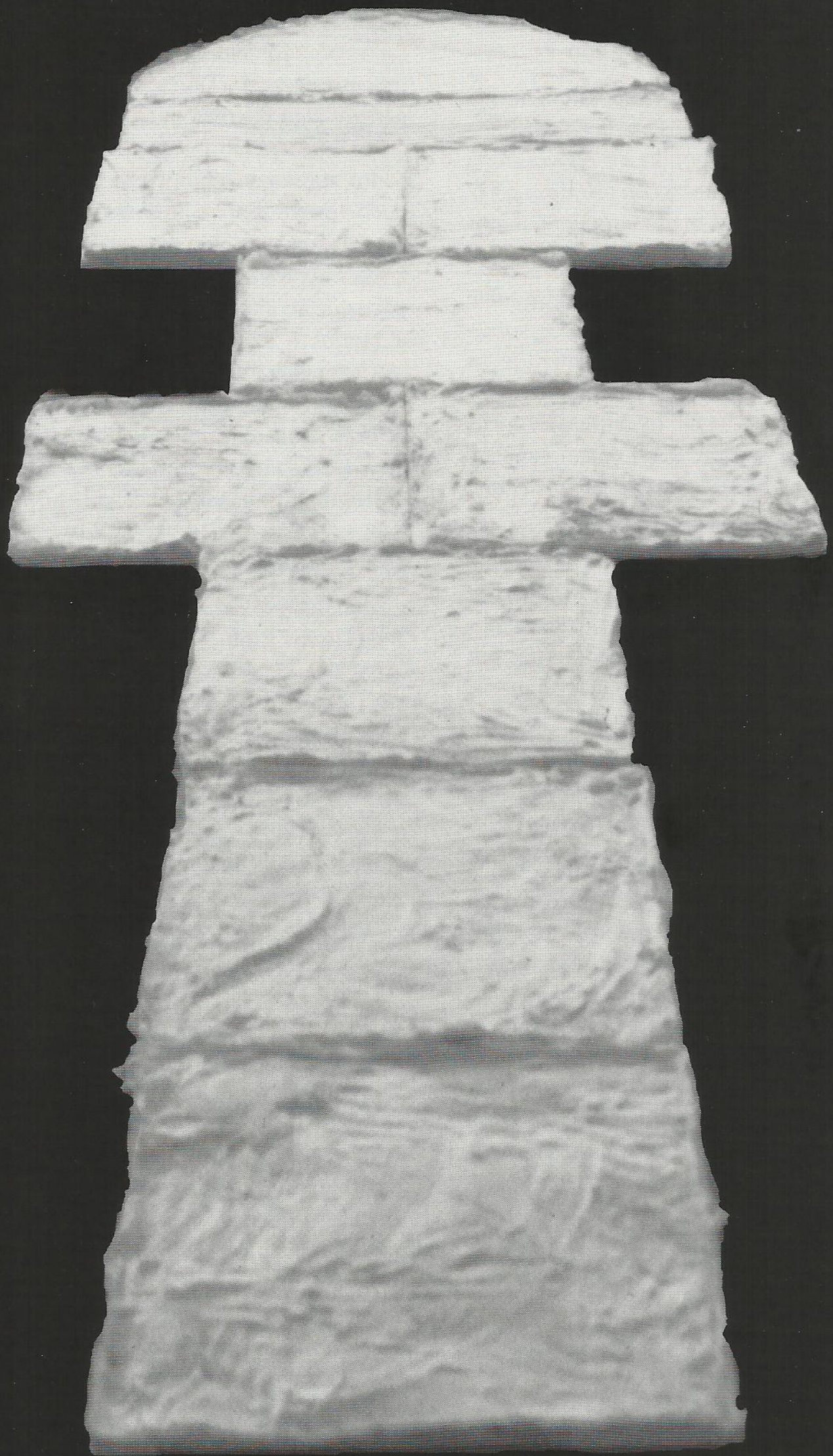

\section{GolosA}

(Instalación) Módulos de yeso y gasa 
Es la ley como la lluvia

nunca puede ser pareja;

el que la aguanta se queja,

pero el asunto es sencillo,

la ley es como el cuchillo:

no ofiende a quien lo maneja².

Catorce textos, catorce alumnos. Más de un aula disponible. Acceso y manejo de tecnologías de información. Muestra anual o bianual del Área de Comunicación. Alumnos entrenados en cumplir con el deber. Variables únicamente pensables en una institución educativa privada.

\section{De los efectos en el ámbito de la escuela privada}

Concebimos el constructo generado como un discurso, es decir, una configuración témporo-espacial de sentido producto de la interacción grupal y de la utilización y resignificación de diversos materiales simbólicos, como ha quedado explicitado desde el relato de la experiencia. Tomando la idea de Eliseo Verón, un discurso, al ser producido en un contexto social dado, no provoca jamás un solo efecto, sino un "campo de efectos posibles" en tanto "el sentido no opera según una causalidad lineal", pues la recepción no es mera descodificación mecánica. Por ello, "del sentido, materializado en un discurso... no se puede dar cuenta con un modelo determinista".

De allí que cada asistente a la muestra atribuyó un sentido a lo recibido y, según Mata (1990: 9), "esa atribución, asentándose necesariamente en los posibles sentidos delineados en el discurso dado, se realiza también en virtud de unas determinadas condiciones de recepción, de unas ciertas competencias comunicativas" y, agrego, de ciertas cargas axiológicas.

Queda claro que no se postula con lo dicho la libertad absoluta del receptor, pues "los discursos tienen la capacidad de configuración de un determinado campo de efectos o sentidos posibles". Si durante el partido las faltas más groseras las cometían el Pibe Coima y Justicia Corrupta; si el partido finalizaba con el triunfo de Fierro y los suyos, pues "más que el sable y que la lanza suele servir la confianza que el hombre tiene en sí mismo"; si al final ambos equipos recitaban a viva voz "los hermanos sean unidos", el sentido estaba predicho en nuestro fútbol sin pelota.

Bueno, pero... ¿qué dijeron los asistentes?

\footnotetext{
2 Ídem 1.
}

"En el trabajo de quinto año no se vio la Literatura" fueron, palabras más o palabras menos, las expresadas por la asesora pedagógica y una de las dueñas de la institución al evaluar lo realizado por quinto año. La directora de Nivel Medio recriminó: "¿Por qué siempre la crítica, por qué no plantear lo positivo, la esperanza?" Un compañero adujo: "Lo que hicieron, vos y los chicos, fue tirar margaritas a los chanchos". Los compañeros del área celebraron la puesta en escena y la apuesta docente. Dos padres se manifestaron positivamente. Uno se quejó por haberse sentido ofendido. Una madre jueza se rió nerviosa. El resto no opinó.

\section{Entre el collage y la hermenéutica}

Difuminar los contornos de lo literario, intentar la hibridación (Martín-Barbero, 1996: 7) de lo literario establecido con cuanta forma de comunicación rodea al adolescente, fue la intención docente. Dicho de otro modo, permitir que eso que la escuela clausura, los famosos contenidos conceptuales, se enriquezcan con los materiales simbólicos provenientes de cuantos ámbitos de interacción vive el alumno, es un intento para lograr evitar el consabido y esperable enfrentamiento con una forma, entre otras, de acceder al conocimiento. La forma que la escuela aclama como más pertinente, aquella que encierra el libro.

La escuela hoy genera barreras para lo que ella cree que es defender el saber. Se planta en un antagonismo vacuo que la aísla del mundo y de los jóvenes. Se pone a la defensiva atacando las tecnologías de la imagen y los medios de comunicación por su "maligna seducción" (Martín-Barbero, 1996: 8). Visualiza la cultura mediática como "sinónimo de maleficio y de manipulación" (Mata, 1990: 16), a la tele como un enemigo ${ }^{3}$. Tal vez porque se haga difícil encontrar el camino para su utilización rentable. Utilización que dista de concebir los medios sólo como herramientas o instrumentos exteriores y auxiliares. Utilización que involucra la apertura, el descentramiento como creo que lo ejemplifica Un fútbol sin pelota.

\footnotetext{
3 "Acosado por los cuatro costados, ese modelo de comunicación pedagógica no sólo sigue vivo hoy sino que se refuerza al colocarse a la defensiva desfasándose aceleradamente de los procesos de comunicación que hoy dinamizan la sociedad... impidiéndose interactuar con el mundo del saber diseminado en la multiplicidad de los medios de comunicación a partir de una concepción premoderna de la tecnología, que no puede mirarla sino como algo exterior a la cultura, 'deshumanizante' y perversa en cuanto desequilibradora de los contextos de vida y aprendizajes heredados" (Martín-Barbero, 1996).
} 
Apertura y descentramiento, hibridación y rumbo incierto generan miedo. Nada más seguro para un profesor inseguro que el Martín Fierro pelado y prolijo de toda la vida, acompañado de algún claro y acotado análisis de un libro de texto. Miedo.

Pero desalojar los miedos desde el hacer creativo es una manera muy gratificante para favorecer la comunicación pedagógica. Es potenciar "la figura y el oficio del educador" (Martín-Barbero, 1996: 9).

\section{Una pedagogía política}

Por ello y desde las palabras de Martín-Barbero la escuela debe "interactuar con las nuevas figuras y modalidades que el entorno informacional posibilita, con los discursos y relatos que los medios masivos movilizan", para no seguir cada día alejándose más y más de su destinatario. "Es sólo a partir de la asunción de la tecnicidad mediática como dimensión estratégica de la cultura que la escuela puede insertarse en los procesos de cambio que atraviesa la sociedad" (Martín-Barbero, 1996: 19).

Reflexionemos ahora en torno a otro desafío que potencia la figura y el oficio del educador, no ya en relación con la utilización de lo mediático. Veamos ahora conectado el desafío con la responsabilidad feliz, junto a otros cientistas sociales, de involucrarnos en la construcción de alternativas desde la práctica social que nos compete: la educación. Vaya si la educación es territorio apto para construir alternativas. En tanto práctica social atravesada por experiencias de comunicación, es necesario y "factible reconocerla como espacio de interacción entre sujetos en los que se verifican procesos de producción de sentido, de creación y recreación de significados, generando relaciones en las que esos mismos sujetos se constituyen individual y colectivamente" (Uranga, 2001: 97). Somos responsables de cómo se constituye el sujeto-alumno en la interacción que proponemos o que aceptamos dentro de los prolijos límites de la escuela privada. Un alumno recipiente que repite lo que le trasvasamos será un ciudadano pasivo que repite lo que el poder hegemónico ordene y organice. Será un actor social y no un autor de nuevas posibilidades. No puede hoy, no podrá mañana generar, ni crear, ni recrear nuevos significados. Si lo modelo en el acatamiento, no podrá "emprender el camino del cuestionamiento", como dice María Cristina Mata.

Conectemos tal responsabilidad feliz con la reflexión de Alfaro Moreno quien expresa que dentro de la complejidad en que vivimos, donde todo nos dice que es mejor callar, pasar desapercibido, estar en el anonimato, crear el mundo posible dentro del ámbito del hogar, protegiéndonos cada día, predicar la conciencia ciudadana o persuadir de manera seductiva sobre la importancia de participar no son caminos convincentes. Resulta fundamental crear una nueva pedagogía política (Alfaro Moreno, 1999: 41).

Postulado claro que orientó el trabajo docente durante todo el proceso de construcción de Un fútbol sin pelota y que debería haber sido la respuesta cuando la institución cuestionó por qué siempre la crítica al momento que vivimos, por qué se habían elegido esos nombres a los jugadores del Power Futbol Club.

¿Qué esperaba esa porción de la comunidad educativa ${ }^{4}$ que cuestionó la representación? ¿Qué concepción de educación escondía el reclamo? ¿Cierta imagen de la escuela como mera transmisora de saberes a memorizar y reproducir, cierto modelo y praxis de comunicación centrado en la secuencia lineal que encadena unidireccionalmente materias, edades y paquetes de conocimientos? Se aduciría un no rotundo, pues teorías provenientes de diversas disciplinas avalan la renovación educativa y la calidad pedagógica de la institución. Mas parece que a la hora de las prácticas, las teorías se archivan.

Para instrumentar esa nueva pedagogía política, de la que nos habla Alfaro Moreno, en el ámbito institucional educativo es necesario un estado de alerta. No podemos transitar acorazados por una ingenuidad tranquilizadora, escudo para la no intervención. Alertas, pues la vida cotidiana impone y legitima con su curso cierta rutina que unifica hegemónicamente el sentido, crea verdades universales y absolutas. Unifica los contenidos conceptuales. Unifica la praxis comunicativa. Unifica la dirección hacia la que deben marchar, según sus dueños, las empresas educativas y sus productos. Unifican y aliñan y amoldan. ¿Desde posturas conscientes, mefistofélicas? Es punto para otra ponencia.

"Hacer estallar tal unificación hegemónica del sentido" (Martín-Barbero) desde los pequeños intersticios que proporciona la vida cotidiana, desde su clandestinidad, tal como nos propone Reguillo junto a de Certeau,

\footnotetext{
4 Comunidad educativa que fue foco de análisis en un trabajo anterior, "La construcción de la alteridad en la escuela privada", publicado en Revista de la Facultad, año 6, № 7, 2002, Universidad Nacional del Comahue, General Roca, Río Negro, Argentina.
} 
es un camino a la esperanza, es una manera de ejercer la reflexividad, de sentir que estamos vivos y podemos insuflar vida en prácticas sociales que aparecen necrosadas.

\section{Cierre con aperturas}

La experiencia relatada intentó dar cuenta de cómo el texto literario, el aula, la institución educativa constituyen un lugar estratégico para pensar la sociedad en su compleja pluralidad de símbolos y de interacciones, en espacio donde se encuentran las prácticas y las estructuras del escenario de la reproducción y de la innovación social.

Creer en la innovación y el cambio, en la posibilidad de "refundar el pacto social" sin el glamour de las grandes revoluciones de otrora -Reguillo dixit-, "soñar un futuro posible" -Uranga dixit-, planificar y gestionar desde prácticas pedagógicas holísticas, auténticas, creativas, es decir, optimizar las oportunidades y recursos que el escenario plantea, es tarea posible y nos compete.

\section{Referencias}

ALFARO MORENO, Rosa María. 1999. "Repensar la política y la comunicación. Trances y apremios para construir ciudadanía". En: WACC, Construyendo ciudadanía, equidad y paz. Retos de la comunicación de cara al 2000. Lima, noviembre.

BARTHES, Roland. 1994. La aventura semiológica. Barcelona: Paidós Comunicaciones.

DO CAMPO, Guajardo, HUENTELAF, MARCHETTI, PADÍN, PEACOCK, SCAIOLA, TORRES. Un fútbol sin pelota, Escuela del Sur, General Roca, Río Negro. Noviembre de 2001.

MARTÍN-BARBERO, Jesús. 1990. "De los medios a las prácticas". En: La comunicación desde las prácticas sociales. Reflexiones en torno a su investigación. México: Universidad Iberoamericana.

1996. "Heredando el futuro. Pensar la educación desde la comunicación". Revista Nómadas, Universidad Central, Bogotá, Colombia.

MARTÍNEZ GUARINO, Ramón. 1996. Estrategias de gestión y microplaneamiento. Buenos Aires: Luimen-Humanitas.

MATA, María Cristina. 1994. Nociones para pensar la comunicación y la cultura masiva. Buenos Aires: La Crujía.

REGUILLO, Rossana. 1998. “La clandestina centralidad de la vida cotidiana". Revista Causas, año V, № 7, Buenos Aires.

URANGA, Wahington. 2001. "Gestionar desde la comunicación, gestionar procesos comunicacionales". Revista Oficios Terrestres, № 9/10, La Plata IV.

VERÓN y SIGAL. 1986. Perón o muerte, los fundamentos discursivos del fenómeno peronista. Buenos Aires: Legasa.

\section{Diálogo del conocimiento}

A partir de una experiencia pedagógica en el Cono Sur del continente, María Lucrecia Reta nos ofrece una profunda reflexión sobre la verdadera función de la pedagogía, transformando el aula escolar en el verdadero canal de comunicación de la sociedad. "Saltar del texto al mundo de la mano de una pedagogía política" desarticula las instituciones pedagógicas arcaicas, a través del desarrollo de nuevos códigos hermenéuticos de dos textos fundamentales de la literatura latinoamericana: El gaucho Martín Fierro (1872) y La vuelta de Martín Fierro (1879) de José Hernández.

El experimento realizado en el quinto año de una escuela privada argentina, que tuvo como resultado final una interpretación futbolística de los dos textos literarios, deja una valiosa enseñanza sobre una nueva función no sólo de los educadores, sino del rol de la literatura y su majestuosa capacidad de ofrecer elementos que permiten descifrar la realidad.

Ese producto estético, fruto de una re-lectura de las obras de Hernández, es para la autora una oportunidad de modificar los canales de comunicación entre alumnos y docentes, transformando el discurso unilateral de emisor-receptor a uno bidimensional emisor/receptor-receptor/emisor, con lo cual se amplían los márgenes de la educación.

Pedagogía política se denomina entonces a esa nueva función de la educación, una labor que debe tener como objetivo específico fomentar la capacidad interpretativa, y por ende crítica, de los estudiantes. En este caso, a través de la lectura de dos obras consideradas patrimonio literario de Argentina, los alumnos lograron no sólo leer, sino dar una valoración estética en la que plasmaron su valiosísima visión del mundo. El objetivo central de todo proceso pedagógico se cumplió: se generó conciencia social.

Sería interesante cuestionarse cómo se podrían adaptar experimentos de este tipo a la enseñanza de la literatura y de las humanidades en general, que en nuestra función de docentes sabemos cimientan y solidifican una visión interdisciplinaria del mundo, elemento fundamental en esta nueva realidad globalizada y pluricultural. Más interesante sería cuestionarse sobre la implementación de esta nueva pedagogía política en un país como Colombia, donde la escuela ha adquirido más conciencia sobre su función social y sobre esa posibilidad que genera el aula, para transformar a los estudiantes en ciudadanos capaces de interpretar la realidad, ofreciendo puntos de vista individuales que son tan sólo el producto del proceso generador de conciencia.

"Saltar del texto al mundo de la mano de una pedagogía política" revalúa magistralmente la misión de los docentes, la magia que encierra el experimento es el elemento literario, el texto como el mundo, y el mundo como un texto con miles de posibles lecturas.

Vanessa Solano Cohen 